\title{
LA CIENCIA, LA TÉCNICA Y LA FILOSOFIA MODERNA
}

\section{Introducción.}

A este siglo se le ha llamado "el siglo de la ciencia". La denominación no es arbitraria ni injustificada. En ninguna edad de la historia, como en este siglo, ha tenido la ciencia una influencia tan preponderante en la vidade los hombres: en sus actos individuales como en su conducta colectiva, en sus obras materiales como en sus ideas y creencias, en ${ }^{t}$ sus decisiones como en sus inhibiciones, en su pasión creadorà como en sus instintos de destrucción, en su concepción del universo como en la apreciación de su propio destino. La ciencia ha asumido la misión que cumplieron en otras épocas la metafísica y la religión. Es un factor decisivo de la historia. Como consecuencia, el mundo de hoy -.en su fisonomía y en su evolución- es un mundo determinado por la ciencia; por sus principios y teoría. Lo científico es, casi sinónimo de lo real, no obstante fundamentales e insoslayables restricciones. Muy rara es 'la' región de la realidad que no haya sido investigada por la. ciencia, explorada en sus fundamentos, explicada por sus conceptos, reorganizada por sus métodos, destituida —en último análisis- de su forma original o primitiva. Inversamente, el trabajo de la ciencia, por alejado que se conciba de la experiencia y de la práctica, incide sobre lo real, iluminando sus estructuras, elaborando su conocimiento o contribuyendo a su transformación. Sus conceptos, sus leyes, sus modelos, su lenguaje, invaden incluso el dominio privativo de lo humano - lo imprevisible y lo incierto-, considerado tradicionalmente como inaccesible por naturaleza a las rígidas formas de la explicación científica. La visión cotidiana de la realidad tiende a identificarse con la visión proyectada por la ciencia.

Pero la época contemporánea es también "el siglo de la técnica". Aunque a menudo se entiende a la técnica como una derivación de la ciencia, aplicación de la ciencia y quehacer subordinado, se trata de disciplinas distintas y de actividades independientes, no sólo en su génesis sino en su esenciá y en sus fines. Ciencia y técnica son, ambas, formas de la razón, pero mientras que la ciencia representa su dimensión teórica, constituye la técnica su dimensión instrumental. La autonomía operativa de la técnica -como lo revela la historia de la cultura - es simétrica de la autonomía teórica de la ciencia. Esta autonomía no ha excluido la colaboración ni los intercambios recíprocos. Procedimientos técnicos han sido deducidos a partir de conocimientos científicos, pero también se han construido teorías científicas para explicar y racionalizar invenciones técnicas, en particular aquellas invenciones 
logradas al margen del saber y de la inspiración de la ciencia. De ahí resulta que problemas técnicos hayan recibido soluciones científicas, en tanto que -a la inversa- soluciones técnicas han planteado problemas a la ciencia, cuya consideración ha sido el origen de nuevos conceptos o nuevos métodos. Llevado a su límite, este proceso de interacción entre ciencia y técnica, de entrecruzamiento de sus problemas y soluciones, constituye uno de los rasgos distintivos irreductibles del siglo actual. Pero este proceso sólo ha sido posible como resultado de una transformación interna tanto de'la ciencia como de la técnica, en cuya virtud la ciencia se ha instrumentalizado y la técnica se ha racionalizado, convirtiéndose en tecnología. Por lo mismo, la instrumentalización de la ciencia es correlativa de la racionalización de la técnica. La ciencia se ha tecnificado; y la técnica, racionalizada, se ha vuelto científica. Esta simbiosis es responsable de la extraordinaria aceleración del progreso que caracteriza al mundo de hoy. La audacia teórica de la ciencia, asociada a la implacable eficacia de la tecnología, representan el mayor y más impresionante de todos los poderes de que dispone el hombre.

La ciencia -en el sentido actual del vocablo_ es una creación de la época moderna, de los siglos xvi y xvir. Lo que hasta entonces se entendía por ciencia era la concepción aristotélico-medioeval del saber. Esta ciencia metafísica, scientia contemplativa, era una abstracción del sentido común y de la experiencia sensorial. Como conocimiento inmediato de las cosas, estaba regida por géneros y categorías incomunicables, por la lógica de la deducción silogística y por el esquema de explicación teleológica y organicista. Era la ciencia del cosmos cerrado y finito, del espacio rebelde a la geometría, del tiempo indiferente a la medida y proyectado hacia la eternidad. Ciencia cualitativa y visual, sólo podía dar cuenta del mundo perceptivo, del mundo ondulante y vario de las formas y colores. De ahí resulta que sus tres presupuestos fundamentales fuesen respectivamente la superioridad de la teoría sobre la práctica, la superioridad de la naturaleza sobre el arte, y la superioridad de la cualidad sobre la cantidad. Por eso también no hubo técnica propiamente dicha en el mundo antiguo y medioeval. No hubo técnica como actividad racional y mecánica; sino más bien como artesanía y como rutina empírica. Puesto que el conocimiento era un fin en sí mismo, no implicaba el manejo de las cosas ni su transformación. Esta concepción de la ciencia prevaleció durante siglos, imponiéndose como evidencia inconmovible, no sólo por el rigor de su construcción sino por su concordancia con el testimonio de los sentidos y con la experiencia cotidiana de las cosas, los que habian sido instituidas no sólo como instrumento de verificación sino también como criterio de validación. Recogida por la tradición cristiana, se mantuvo casi inalterable hasta el advenimiento de la época moderna. Tan durable influencia, tan persistente predominio, sólo pueden explicarse por su coherencia interna, por su fuerza persuasiva, por su rigor apodíctico. 
Por eso, la ciencia moderna no pudo constituirse sino como resultado de una radical revolución intelectual, una verdadera creación de instrumentos mentales y cognoscitivos. En efecto, la ciencia moderna se instauró, por una parte, como oposición y ruptura con la síntesis aristotélica dominante; pero, por otra parte, tras un largo y complejo proceso, construyó conceptos y métodos, que no sólo revocán en duda el saber tradicional y su indiscutida autoridad, sino que concurren a la formación de úna nueva imagen del mundo, una nueva teoría del conocimiento, un nuevo modo de pensar, una nueva relación con la naturaleza, una nueva idea del hombre y de su destino. En definitiva: una nueva filosofía. Desde entonces se entiende por ciencia al conocimiento objetivo de la naturaleza, mediante el establecimiento de las leyes. que la rigen y que permiten explicar sus fenómenos y predecirlos. Saber es no sólo dar cuenta de lo conocido sino además anticipar lo desconocido. Si se conoce a la naturaleza, si se conocen las propiedades de las cosas, si se puede predecir el comportamiento de los procesos naturales, entonces también es posible intervenir en su curso y modificarlos en función de su utilidad para la vida humana. La teoría ilumina a la práctica como el arte se impone sobre la naturaleza. Saber no es sólo explicar; saber es también poder. La ciencia adquiere así una nueva dimensión. Es un póder de intervención, multiforme y multivalente, universal y abstracto, capaz de transformar al mundo y al hombre mismo. Con la nueva ciéncia no está el hombre al servicio de la naturaleza, sino la naturaleza al servicio del hombre. La nueva ciencia es scientia activa et operativa.

En contraste con la ciencia aristotélico-medioeval, la 'nueva ciencia contradice resueltamente al sentido común y a su pretendida evidencia. Su dominio no es el mundo de la percepción, sino el mundo de la inteligencia y de sus relaciones, por lo que substituye a la categoría de cualidad por las leyes matemáticas y al esquema teleológico y organicista por el esquema causal y mecánico. Mientras que la ciencia aristotélico-medioeval se regía por el principio de incomunicabilidad de géneros, la nueva ciencia destruye el concepto mismo de género y con ello introduce en el conocimiento de la naturaleza la maravillosa eficacia de las matemáticas. Al revocar el testimonio. de la experiencia cotidiana, instituye como método de verificación la prueba por la experimentación; y la observación ya no es entonces lo que revelan los órganos de los sentidos, sino lo que recogen aparatos e instrumentos téc-. nicos. La instrumentalización de la ciencia admite así una doble significación: de un lado, es la implantación de instrumentos como órganos del conocimiento; y de otro lado es la conversión del saber en instrumento de transformación. La nueva ciencia constituye - según la clara expresión de Koyré - el tránsito del "mundo del más o menos" al "universo de la precisión", lo que implica a la vez tanto la geometrización del espacio como la aritmetización del tiempo, es decir, el definitivo abandono del concepto de 
cosmos finito y su reemplazo por el de universo infinito y sin límites. Para la nueva ciencia, es la teoría solidaria de la práctica, el arte rival de la naturaleza, la cantidad superior a la calidad. Su fundamento no es ya metafísica de la substancia y del concepto sino la metafísica.del sujeto y de la representación.

Por su orientación utilitaria, por su estructura matemática, por su voluntad de dominio sobre la naturaleza, la ciencia moderna -activa y operativa - se prolonga y se completa en la técnica y emprende la prodigiosa aventura de transformar al mundo, de dominar a la naturaleza por medio de la razón y someterla a los fines humanos. Esa aventura es la grandeza y la miseria del hombre moderno. La asociación de "theoría" y "práxis", de conocimiento y acción, de ciencia y técnica, de saber y poder, no es fortuita ni accidental sino que está inscrita en la esencia y en el proyecto de la ciencia moderna. Es una verdadera conversión intelectual. El interés de la inteligencia se vierte hacia las cosas para incorporar la teoría en la práctica, regir la acción por el conocimiento, poner la ciencia al servicio de la técnica. Con ello se establece la condición de posibilidad práctica del maquinismo y la industria. Esta conversión intelectual subtiende a la filosofía cartesiana. Nadie formula mejor que Descartes los intereses de la nueva ciencia, que él habia contribuido a crear. "Pero desde que hube adquirido - dice Descartesalgunas nociones generales tocantes a la física y que, comenzando a ponerlas a prueba en diversas dificultades particulares, observé hasta dónde ellas pueden conducir y cuánto difieren de los principios de que uno se ha servido hasta ahora, he creído que no podia tenerlas ocultas sin pecar grandemente contra ĺa ley que nos obliga a procurar tanto como nos es posible el bien general de todos los hombres porque ellas me han hecho ver que es posible alcanzar conocimientos que sean muy útiles a la vida y que, en lugar de esta filosofía especulativa que se enseña en las escuelas, se puede encontrar una (filosofía) práctica, por la cual conociendo la fuerza y las acciones del fuego, del agua, del aire, de los astros, de los cielos y de todos los otros cuerpos que nos rodean tan distintamente como conocemos los diversos oficios de nuestros artesanos, podríamos emplearlos de la misma manera a todos los usos a los cuales son propios y volvernos así como dueños y posesores de la naturaleza." ' Que las nociones generales de la física pudiesen servir para resolver "diversas dificultades particulares", constituía a los ojos de Descartes un descubrimiento de la más grande importancia, un descubrimiento que habria de ser decisivo tanto para su vocación intelectual como para el curso futuro de sus propios trabajos. En efecto, por "dificultades particulares" entiende Descartes "problemas concretos" (cfr., "dificultades de las matemáticas" $^{\prime 2}$, que se plantean no en el interior de la física sino en el dominio de la

1 Cfr. Descartes; Discours de la Méthode, IV; Paris (Ed. de la Pléaide), p. 168.

2 Ibid., p. 145 . 
práctica y de la vida cotidiana. Una disciplina especial como la óptica, por ejemplo, 'que interesó a Descartes desde su juventud, podía servir para resolver problemas técnicós relativos a la construcción de lentes, espejos o anteojos, pero al mismo tiempo dejaba al descubierto un horizonte insospèchado e insólito, porque hacía factible la invención de instrumentos de observación científica como el telescopio y el microscopio, que revolucionaban a la ciencia misma. Los conocimiéntos ópticos -que son de naturaleza teórica - intervienen así de modo directo en la práctica, confiriéndole un nuevo sentido y una nueva dimensión. La práctica se racionaliza y se vuelve técnica: Cuando falla la rutina, cuando el tanteo es ineficaz, cuando el empirismo revela su impotencia, aporta la ciencia el concurso de sus conceptos y leyes, introduciendo la coherencia, la seguridad y el rigor. Inversamente, cuando falta a la teoría el sustento real; cuando sus hipótesis no se pueden confirmar, cuando sus condiciones no se cumplen en la naturaleza, entonces la práctica - en la forma de la técnica- ingenia los recursos necesarios para efectuar artificialmente las condiciones de la teoría, substituyendo la experiencia del sentido común por la verificación experimental y controlada. Descartes intuye que la cienecia puede prolongarse en la realidad, que la física no es un sueño del espíritu, que teoría y práctica se prestan recíprocos e indispensables servicios. Al lado del mundo natural, complicado y diverso, puede coexistir un mundo de artefactos y autómatas, cuya finalidad es transformar las condiciones materiales de la vida y concurrir al bienestar y a la felicidad de los hombres.

Así se estáblece la esencial distinción entre el útil y el instrumento. Un par de anteojos es un útil, porque prolonga y potencia el sentido natural de la vista. En cambio, un telescopio es un instrumento en cuanto sobrepasa al sentido común, revela cosas que jamás habían sido percibidas y provee a la ciencia dé un medio de observación y de descubrimiento, que satisface a su espíritu de precisión y a su exigencia de exactitud. ${ }^{3}$. Un instrumento es producto de la ciencia, realización de sus teorías. No se pudo inventar el telescopio sino cuando Galileo — según una difundida versión acaso falsa- hizo la teoría todavía sumaria e imperfecta de los ángulos de refracción y utilizó lo que hasta entonces no era sino un larga-vista para la observación astronómica. No se pudo inventar el reloj de péndulo sino cuando Huygens descubrió el isocronismo del movimiento cicloidal, proporcionando a la ciencia por primera vez en la historia la posibilidad de una medida exacta del tiempo. El telescopio y el reloj de péndulo, instrumentos científicos por excelencia, no sólo porque tienen un origen inmediato en la ciencia sino porque pertenecen propiamente a su ámbito, constituyen el punto de partida del universo de la precisión, que es el universo inaugurado por la ciencia moderna. El telescopio y el rèoj de péndulo, por otra parte, no son invención de los artesanos ni

3 Cfr. Alexaridre Koyré, Études d'histoire de la peñsée philosophique (Paris: Librairie Armand Colin, 1961), p. 321. 
resultan de su habilidad. En sentido estricto, son creaciones de la óptica, es decir, de la física.

Cuando Descartes opone las "nociones generales" de la física a los "principios" de la filosofía especulativa, no quiere significar con ello que la ciencia sea la teoría de la práctica, sino más bien que la física es superior a la escolástica en lo que respecta a la transformación material del mundo. Por lo mismo, el valor de los conocimientos no reside en su eficacia pragmática sino en su verdad racional. La verdad de los conocimientos es condición de su eficacia y de su utilidad. El saber no es verdadero porque se puede aplicar en la práctica, sino se puede aplicar en la práctica porque es verdadëro. Conocer "la fuerza y las aciones del fuego, del agua, del aire, de los astros, de los cielos y de todos los otros cuerpos que nos rodean" equivale a constituir la ciencia física, la física matemática, cuyas leyes gobiernan al universo y deben inspirar y presidir el trabajo de la técnica. Pero hay que conocer estas fuerzas y estas acciones "tan distintamente como conocemos los diversos oficios de nuestros artesanos", por lo que el conocimiento no puede ser especulativo sino operativo. Como conclusión, Descartes enuncia el principio fundamental de la época moderna: convertir a los hombres en amos y posesores de la naturaleza.

La voluntad de poder cambia de signo. Reyes y príncipes gobiernan la vida política y social; la Iglesia y sus doctores gobiernan la vida intelectual y espiritual. Sólo la ciencia puede y debe gobernar la vida material, conociendo a la naturaleza y sirviéndose de este conocimiento como instrumento de poder. La voluntad de poder cobra así la forma de voluntad de transformación, al servicio del bienestar humano. Por eso, también, Descartes considera como un pecado ocultar sus conocimientos: un pecado contra la humanidad. De ahí resulta la vocación pública de la inteligencia científica, es decir, la necesidad de publicar, dịfundir y propagar el saber, cuando el saber es útil para la vida del hombre, cuando puede aliviarlo de trabajos penosos como la mecánica, cuando puede contribuir a conservar la salud y prolongar la existencia como la medicina. La utilidad de la ciencia no consiste - como lo era para el pensamiento clásico antiguo en aumentar la virtud y elevar el espíritu a la contemplación de la verdad. La utilidad de la ciencia $\rightarrow$ como lo proclama Descartes - consiste en enriquecer la vida y hacer del hombre amó y señor de la naturaleza. La doctrina cartesiana asigna a la filosofía una nueva dignidad. Su cometido ya no es la sálvación del alma sino la conquista del mundo y la felicidad" de todos los hombres. "Así toda la filosofía - escribe Descartes en el prefacio de los "Principios"- es como un árbol cuyas raíces son la metafísica, cuyo tronco es la física y las ramas que salen de ese tronco son todas las otras ciencias, que se reducen a tres principales, a saber, la medicina, Ia mecánica y la moral; y y entiendo por ella la más alta 
y la lámás perfecta moral, que al presuponer un entero conocimiento de las otras ciencias, es el último grado de la sabiduría." 4

El concepto cartesiano de filosofía incluye a todas las ciencias, pero instaura a la metafísica como su necesario fundamento, como las raíces que nutren y sustentan al árbol del saber. Todas las ciencias pueden reducirse a tres principales: la medicina, la mecánica y la moral, es decir, las ciencias que intervienen directamente en la vida de los hombres: en la vida biológica, en la vida material y en la vida espiritual. Sin embargo, una ciencia - la mecánica- domina a todas las otras. Muy temprano concibe Descartes al modelo tecnológico de la máquina como principio de explicación científica. La eficacia de las máquinas, la estructura de sus componentes, el funciónamiento de sus mecanismos, sirven para explicar al organismo humano y animal y, por extensión, a la naturaleza en su conjunto. "Para ello" - dice Descartês en los "Principios", refiriéndose a sus doctrinas - "me ha servido múcho el ejempló de varios cuerpos, compuestos por el artificio de los hombres, púes no reconózco ninguna diferencia entre las máquinas que hacen los artesanos y los diversos cuerpos que la naturaleza por sí sola compone, sino que los efectos de las máquinas sólo dependen de la combinación de ciertos tubós o resortes u otros instrumentos que, debiendo guardar algunas proporciones con las manos de quienes los hacen, son siempre tan grandes que pueden versé sus figuras y movimientos, en tanto que los tubos o resortes que causan los efectos de los cuerpos naturales son de ordinario demasiado pequeños para que los perciban nuestros sentidos. $Y$ es cierto que todas las reglas de las mecánicas pertenecen a la física, de modo que todas las cosas que son artificiales, son por ello naturales. Pues, por ejemplo, cuando un reloj marca las horas ipor medio de las ruedas de que está hechò, ello no le es ni más ni menós natural que lo es para un árbol producir sus frutos. Por eso, del mismo modo que un relojero, viendo un reloj que ha hecho puede de ordinario juzgar por algunas de las partes que observa cuáles son las otras que no ve; asi, considerando a los efectos y a las partes sensibles de los cuerpos naturales, he tratado de conocer cuáles deben ser aquellas partes que son insensibles" (i.e. inaccesibles a' los sentidos). ${ }^{5}$

$\therefore$ Descartes presupone, en consecuencia, que la máquina está construida a imagen del cuerpo naturàl, que el arte o la técnica imita a la naturaleza y que; por último, los mecanismos de los artefactos reproducen los procesos naturales a la escala "del hombre. Toda la ciencia reposa sobre un axioma fundamental implicito: lo invisible se explica por lo. visible. Por eso decía Bachelar, en una fórmula admirable: "no hay ciencia sino de lo que está oculto:". Para la ciencia cartesiana, lo visible es la máquina, el artefacto, el instrumento. A partir de la máquina facticia se puède comprender la máquina

4 Descartes, Oeuvres et Lettres (Paris: Ed. de la Pléiade), p. 566.

"5 Descartes, "Les principes de la philosophie", art. 203 (Paris: Ed. dé la Pléiade), p. 666. 
natural, sobre todo en aquellos aspectos que son inaccesibles a los sentidos humanos. La explicación mecanicista, que Descartes inaugura o consolida en la historia del pensamiento, consiste, por lo tanto, en la transposición de la tecnología de la máquina a la naturaleza y sus procesos. Además -como escribe Koyré- "el acto de la inteligencia que, descomponiendo y recompo. niendo una máquina, comprende su agenciamiento, así como la estructura y el funcionamiento de sus piezas múltiples, es exactamente análogo a aquel por el cual, descomponiendo una ecuación en sus factores, la inteligencia comprende la estructura y la composición". 6 .

Para la doctrina cartesiana, por consiguiente, la diferencia entre lo natural y lo artificial no es tan drástica e insalvable como lo es para el pensamiento aristotélico. Lo artificial es, en última instancia, un modo o expresión de lo natural. En efecto, el artefacto se produce por imitación de la naturaleza. Las reglas de la mecánica -ciencia de las máquinas- son al mismo tiempo reglas de la física, ciencia de la naturaleza. Por lo tanto, "las cosas que son artificiales, son por ello naturales". De otro lado, tan espontáneo es el funcionamiento de la máquina, una vez construida, como el funcionamiento de los organismos naturales, porque ambos -en último análisisobedecen à las mismas leyes. El mecanicismo aparece así como una inflexión natural de la inteligencia, como una tendencia que nace espontáneamente de la consideración de los problemas científicos. Aunque insuficiente, inadecuada o falsa, la explicación mecánica ha tenido una influencia decisiva en el progreso del conocimiento y en la constitución de la imagen científica del universo. La máquina, que es encarnación de la teoría, recibe así su justificación filosófica. No sólo es el instrumento principal de la transformación del mundo sino al mismo tiempo su principio de explicación, su modelo y su representación. La máquina justifica a la ciencia como la ciencia justifica a la máquina. En esta circularidad reside la prueba de que el mecanicismo es una explicación de orden global, una explicación que abarca a la totalidad del universo, porque una doctrina es total sólo cuando -como lo señala Hegel - el principio y el fin coinciden, como en el círculo.

De las consideraciones precedentes resulta que la ciencia moderna, en sus comienzos históricos, prefigura al mundo actual, porque contiene in statu nascendi los elementos y fuerzas, cuyo desenvolvimiento casi lineal, casi previsible, conduce al predominio de la ciencia y de la técnica. Por eso, el mundo actual no es una irrupción brusca e inesperada en el escenario de la historia. El mundo actual, como teoría y como proyecto, es obra lúcida y exclusiva de la filosofía moderna - de la filosofía moderna, cuyo padre indiscutido es el mismo Descartes, pensador de la soledad y de la claridad.

Algunos años antes, Francis Bacon había precedido a Descartes en el presentimiento y proyecto de un mundo transformado por la ciencia y por 'c Cfr. Koyré, op. cit., p. $3^{16}$. 
la técnica. Con fervờòsa elócuencia, con entusiảsmo de neófito, Bacón sproclama su convicción -novedosa e insólita en la época- de que la naturaleza puede ser dominada por el saber, por un saber renovado en su objeto; en su estructura y en su método. Por su talento literario, su fuérza persuasiva, su genio divinatorio, èjercitó una considerable influeñcia en la formación de un clima cultural favorable y receptivo a los ideales de la modernidad, que comportaban la apertura del conocimiento hacia la acción, la promoción de lo práctico y utilitario, el ennoblecimiento de las artes mecánicas y del trabajo, menospreciados hasta entonces por una civilización cuyos valores aristocráticos condenaban a la industria humana como menesteres serviles $\mathrm{e}$ indignos. No obstante úna leyenda tenaz, recogida y magnificada por la interpretación positivista de la historia, no es Bacon êl fundador de la ciencia moderna, sino más bien su profeta y su heraldo. No fue un científico, sino un erudito y un artista, lo que explica la vâsta difusión de sus ideas y de sus obras, donde la intuición justa coexiste con juicios erróneos, donde lá palabra brillante hace olvidar a menudo falsas doctrinas y reglas inaceptables.

Contra la cultura tradicional, Bacon reclama un nuevo saber, a la vez experimental, inductivo y operativo, capaz de arrancar a la naturaleza" sus secretos y misterios y ponerlos al servicio del hombre. En una época todavía dominada en lo esencial por aristotélicos y escolásticos constituía un mérito inmenso romper con la autoridad de la tradición y proponer al mismo tiempo un proyecto positivo y audaz. "El fin verdadero y legítimo de las ciencias -dice Bacon- no es otro que el de dotar a la vida humana de nuevos inventos y de nuevas riquezas." " Nuevos inventos, es decir, creaciones-técnicas y mecánicas. Nuevas riquezas, no en sentido moral y espiritual, sino en sentido material. La orientación pragmática de la nueva ciencia queda así definida con toda claridad. Ese fin no lo cumple la ciencia tradicional. Por eso, buena parte de la obra de Bacon está dedicada a "destruirla", mostrando la inadecuación de sus principios, la falsedad de sus acertos y la ineficacia de sus métodos. Aunque la crítica no sea siempre fundada, aunque la elocuencia y el fervor substituyan a menudo al rigor conceptual, no es menos cierto que ella ataca a la concepción aristotélico-medioeval en sus aspectos fundamentales, en su impotencia para unir el conocimiento y la acción, para hacer de la ciencia no una colección de silogismos sino el efectivo instrumento de intelección y conquista de la realidad.

El saber tradicional está formado por las "anticipaciones de la naturalèza", es decir, por el producto espontáneo de la razón humana. Es un conocimiento "fortuito, maquinal y prematuro", cuya posesión es inútil e impide concebir ilusiones y esperanzas de progreso. A las anticipaciones, opone Bacon las "interpretaciones de la naturaleza", que son los conocimientos "ex-

7 F. Bacon, Instauratio magna, I. 
traídos de las cosas, observadas y analizadas con método".. ${ }^{8}$ Las anticipaciones son falsas, porque proceden del libre ejercicio del entendimiento, cuya vocación natural, en ausencia del método y de sus reglas, lo conduce a la abstracción y al divorcio con las cosas, a la aceptación de prejuicios, convenciones y creencias que obsesionan al espíritu, distorsionan su visión y lo desvían de la verdad. La crítica de los principios del saber tradicional adquiere asi la forma de una refutación, de una destrucción de los obstáculos que se oponen al verdadero saber y que Bacon designa con el nombre genérico de idola, esto es, imágenes o fantasmas. Los idola son de diversas especies y conciernen a los múltiples aspectos de la vida humana: prejuicios infundados, máximas impropias, ideas recibidas, generalizaciones abusivas, ambigüedades en la expresión, sofismas y paradojas, doctrinas metafísicas o religiosas. Destruir los idola es entonces una catarsis indispensable al logro de la ciencia. Lo que Bacon emprende, en último análisis, es una crítica global de la cultura. A la luz del proyecto del nuevo saber, analiza todo el legado cultural en sus aspectos más importantes, discutiendo sus supuestos, impugnando sus convenciones y símbolos, denunciando sus supersticiones, mistificaciones y fabulaciones, convirtiendo a la ruptura con la tradición en una "tabula rasa" de la inteligencia, 'cuya liberación es condición previa para acceder al conocimiento cientifico.

Al lado de la crítica de los principios, Bacon desarrolla también una crítica de los conceptos fundamentales, físicos o metafísicos, de la ciencia aristotélico-medioeval. "Nada es más falso" - escribe Bacon_- "o más incierto que las nociones recibidas, sea en lógica, sea en física, como las de substancia, cualidad, acción, pasión, y la noción misma de 'ser'; todo eso no vale absolutamente nada. Menos todavía se puede presuponer las nociones de densidad y rarefacción, gravedad y ligereza, humedad y sequedad, generación y corrupción, atracción y repulsión, elemento, materia y forma ni una infinidad de otras semejantes, que son todas nociones fantásticas y mal definidas". ${ }^{9}$ En este único aforismo aparecen recusadas tanto la tabla de categorías lógicas como las bases mismas de la física y de la metafísica aristotélicas. Es una condena vigorosa y rotunda de la tradición, que habrá de prolongarse bajo formas y expresiones diferentes durante toda la etapa inicial de la época moderna. Más tarde, Descartes expresará la misma rebeldía ante el pasado, la misma exigencia de reconstruir desde sus cimientos el edificio entero de la cultura. Acaso los hombres que fundaron la ciencia moderna tuvieron clara conciencia de que la construcción del nuevo saber implicaba una ruptura tan radical como irreversible. Pero Bacon se limita a condenar la tradición y no la renueva ni la transforma. Los nuevos conceptos y las nuevas categorías de la ciencia moderna serán la obra paciente y prodigiosa de Galileo, Des-

8 F. Bacon, Novum organum, I, 26.

- Ibid., I, 15 . 
cartes, Newton, Huygens y Leibniz. El propio Bacon conserva todavia la teoría de las cuatro causas, la superioridad de la categoría de cuálidad sobre la de cantidad, la búsqueda de la esencia o forma como constitutiva del conocimiento. La ley es para Bácon ley de un "acto puro".

Por último, Bacon critica los métodos del saber tradicional, en particular 'la lógica del silogismo, considerada como el único "órganon" del conocimiento. Éste es quizá el aspecto más audaz de su combate contra el aristotelismo. "El silogismo" - dice Bacon - "no tiene ninguna utilidad para inventar o verificar los primeros principios de las ciencias. Sería en vano que se quisiera emplearlo para los principios medios. Es un instrumento demasiado débil y demasiado grosero para penetrar en las profundidades de la naturaleza. Así se ve que su poder es total sobre las opiniones y que es nulo sobre las cosas mismas". ${ }^{10}$ En efecto, el silogismo no es un instrumento de invención, en el sentido de adquisición e incremento del saber. No es tampoco un instrumento de verificación cognoscitiva. La utilidad del silogismo sólo se revela en el proceso formal de la demostración lógica. La crítica de Bacon pone en evidencia, por consiguiente, la incapacidad irremediable de la lógica silogística no sólo para obtener conocimientos y enriquecer el saber sino también para probar lo que se ha establecido por la observación o por la experiencia. No es su empleo sino su estructura misma lo que inhabilita al silogismo como método de la ciencia. El conocimiento no es un proceso cerrado, por lo que la inferencia silogística, que no es sino la explicitación de lo que está contenido en las premisas, se condena en el límite a la repetición y a la tautología. Pero si lo que se busca es sólo establecer rigurosa, correcta e inobjetablemente una verdad ya adquirida, entonces el silogismo es un método incomparable y tal vez irreemplazable. Lo que, en definitiva, impugna Bacon en la lógica aristotélica es la identificación de la teoría de la deducción, que es indiscutiblemente más rica y más amplia, con la teoria simple y esquemática de la deducción silogística.

Sobre la base de esta crítica de principios, conceptos y métodos, Bacon propone una nueva ciencia fundada en la experimentación, regida por la lógica de la inducción y orientada hacia la acción y la práctica, una nueva ciencia que asocie lo racional y lo experimental. Como el método es el aspecto esencial de saber, la nueva ciencia reclama un "Novum Organum", que substituya al viejo "Organon" aristotélico, responsable de la"ignorancia con respecto de la naturaleza y de la impotencia del hombre para dominarla y transformarla. El "Novum Organum" es la lógica y la metodología de la nueva ciencia. Su principio es la inducción como instrumento de adquisición de conocimientos y la experimentación como método de verificación. Bacon 'las reúne en la unidad de una misma técnica intelectual, que es el fundamento de la reforma del entendimiento que preconiza. "Y aunque haya en- 
teramente desconocido" - dice Meyerson en su clásico libro Identité et Réalité- o más expresamente negado la importancia, en la ciencia, de los elementos no empíricos, el hecho de haber elocuentemente proclamado, en una época en que sólo la deducción estaba en honor, la necesidad de las investigaciones experimentales, constituye el mérito imperecedero de Bacon..$^{11}$

Lo que Bacon entiende por "inducción" no es la inducción aristotélica, de la que se distingue por su materia y por su forma. La inducción aristotélica es una "totalización" del saber adquirido. Su esquema es el siguiente: " $A, B, C, D$ tienen una misma ṕropiedad $P$. Pero $A, B, C, D$ son todos miembros de un conjunto o especies de un género. Luego, $P$ es una propiedad del conjunto o del género." La inducción aristotélica no es un silogismo, puesto que su forma no corresponde a ninguna de las figuras admitidas. Es un simple proceso de comprobación, fundado en la enumeración finita. Dada una colección de objetos $C$ y una propiedad $P$, se trata de comprobar si todos los objetos de la colección, uno por uno, admiten la propiedad $P$, en cuyo caso se afirma que la colección $C$ posee la propiedad $P$. En cambio, la inducción baconiana o amplificante, como la denominan los tratados de lógica, es un método de investigación y descubrimiento, que trata - según la expresión de Goblot - de "encontrar y probar por el examen de los hechos las leyes que lo rigen"."12 Siendo la ley "una relación constante entre los hechos"; la inducción amplificante extiende a un número infinito de hechos la ley que ha sido observada sólo en un número finito y además pequeño. Este paso de lo finito a lo infinito constituye la dificultad esencial de la inducción amplificante, pero al mismo tiempo le confiere su poder y su eficacia en la investigación cientifica.

Bacon condena la inducción aristotélica por considerarla un "método infantil", que conduce a "conclusiones precarias" y está expuesta a 'ser invalidada por el "primer ejemplo contradictorio". En cambio, "la forma de in-" dución verdaderamente útil en la invención o en la demostración de las ciencias se toma de una manera muy distinta: ella analiza las operaciones de la naturaleza, hace una selección entre las observaciones y experiencias, desprendiendo de la masa, por exclusiones y desechamientos convenientes, los hechos no concluyentes; luego, después de haber establecido un número suficiente de proposiciones, se detiene al cabo en las proposiciones afirmativas y se mantiene en ellas". ${ }^{33}$ Lo que Bacon designa con el nombre de "inducción" no es, por lo tanto, lo que Aristóteles entiende con ello. El único rasgo común es el resultado que se obtiene, es decir, la generalización de una proposición. La inducción aristotélica generaliza por enumeración directa; la inducción baconiana lo hace por eliminación y exclusión. Por otra parte, la inducción

11 Emile Meyerson, Identité et Réalité (Paris: Librairie Vrin, 1951), p. 464.

12 E. Goblot, Traité de logique (Paris: Librairie Armand Colin, 1947), p. 289 .

13 F. Bacon, Novum organum, 105. 
aristotélica está asociada a la lógica de la deducción y de la demostración, mientras que la inducción baconiana está asociada a los métodos de investigación y experimentación, cuya norma no es la necesidad lógica sino la eficacia cognoscitiva. Bacon pone el acento en dos momentos principales de la inducción: el análisis dé las operaciones de la naturaleza y la selección mediante eliminación y exclusión de los hechos no concluyentes. El análisis de las operaciones proporciona un conjunto de datos de diversa índole; sobre esos datos, se opera una selección con ayuda del criterio de presencia o ausencia de aquello que se busca. Si, por ejemplo, se trata de encontrar la esencia o forma del calor, será necesario reunir por analogía todos aquellos ejemplos en donde está presente el calor, como los rayos del sol, los meteoros, los relámpagos, las erupciones de los volcanes, cualquier especie de llama, etc. Al mismo tiempo, se tratará de encontrar ejemplos que revelan la ausencia o el decrecimiento del calor, como los rayos de la luna, los cometas, relámpagos luminosos, erupciones volcánicas de zonas árticas, etc. Puede ocurrir que un ejemplo de presencia no encuentre su correspondiente ejemplo de ausencia, como es el caso de la llama producida por el fuego. El conjunto de estos ejemplos se dispone en forma de tablas de presencia o de ausencia. Análogamente se pueden establecer tablas de comparación o de grados, es decir, ejemplos de los cuerpos cuya temperatura natural es superior o inferior al tacto humano. De este modo, Bacon construye diversos esquemas operativos, destinados a servir al estudio de la naturaleza, como las figuras del silogismo que sirven a los fines de la demostración. Las tablas de presencia, ausencia y comparación, aplicadas mecánicamente, como las reglas silogísticas, debían constituir las normas de la nueva lógica. Aunque tales esquemas - como observa pertinentemente Meyerson- no han sido utilizados por ningún científico digno de ese nombre ni han dado origen a ningún descubrimiento, ${ }^{14}$ contienen sin embargo la idea de procedimientos inductivos, que habrían de ser sistematizados más tarde por Stuart Mill y que se conocen con los nombres de métodos de concordancia, diferencia y variaciones concomitantes. El propio Stuart Mill agregó el procedimiento conocido como método de los residuos. Por su intención más que por sus actos, Bacon ha sido considerado por la historia como el primer teórico del método experimental. La experimentación aparece así como el rasgo capital de la nueva ciencia, porque - como dice Goblot- "no solamente tiene por finalidad una toma de posesión de las potencias naturales por la voluntad del hombre, sino también de hacer a la naturaleza inteligible; tiende a someterla no sólo a la voluntad del hombre, sino también a su inteligencia". ${ }^{15}$

Además de una nueva lógica, Bacon propone una nueva relación entre el hombre y la naturaleza. En efecto, de la ciencia tradicional se deduce la

14 Meyerson, op. cit., p. $: 448$.

15 E. Goblot, op. cit., pp. $285^{-86}$. 
idea de que la naturaleza es un espectáculo, que el hombre contempla asombrado, aterrado o indiferente. La naturaleza es intangible. Pero la pasividad no es compatible con el proyecto de la ciencia activa y operativa. "El hombre -dice Bacon, en el primer aforismo del Novum Organum_, intérprete y servidor de la naturaleza, sólo produce y conoce cuanto ha observado por el experimento o por la mente en el orden de la naturaleza, pero por encima de esto no puede ni sabe nada." ${ }^{16}$ Esta definición no es intrínseca sino extrínseca. El hombre no es determinado desde su propio punto de vista, sino. desde el punto de vista de la naturaleza y de la ciencia. No importa tanto lo que el hombre es en sí mismo, sino lo que el hombre es con respecto de la naturaleza y de la ciencia. El hombre es intérprete (interpres) es decir, lector de signos, descifrador de enigmas y misterios; y es ayudante o servidor (minister) es decir, elemento activo, agente, capaz de participación e intervención. De aquí se deduce un doble concepto de naturaleza: la naturaleza libre (natura libera) y la naturaleza intervenida (natura vexata). La naturaleza es libre cuando está regida por su propia espontaneidad, cuando sigue su propio curso, cuando sus fuerzas y procesos se despliegan al margen de toda influencia. La naturaleza es intervenida o maltratada cuando el hombre violenta su curso espontáneo y le impone su voluntad. Bacon reconoce al hombre el' derecho de intervenir la naturaleza, de interferir en su actividad y de transtornar sus procesos, siempre que con ello se puedan adquirir conocimientos. Además, dejada en libertad, la naturaleza esconde sus secretos. "A la naturaleza —decía Heráclito_ le gusta ocultarse.”. Por eso, la violencia puede ser un instrumento de conocimiento. "En las relaciones ordinarias de hombre a hombre" —dice Bacon_. "el método más seguro para descubrir. lo que es natural así como los secretos sentimientos de cada individuo es observarlo en sus momentos de inquietud y de viva emoción. Ocurre lo mismo con los misterios de la naturaleza: ella deja más fácilmente escapar su secreto, cuando es atormentada y como torturada por el arte que cuando se la abandona a su curso ordinario, dejándola en completa libertad. ${ }^{17}$ La nueva ciencia no admite, por lo tanto, ni al hombre como espectador ni a la naturaleza libre y espontánea. Más tarde Descartes habrá de radicalizar la fórmula de Bacon: el hombre no es sólo intérprete y servidor sino amo y posesor de la naturaleza sobre la base del saber. Entre el hombre y la naturaleza se instituye un diálogo permanente, puesto que el saber no es otra cosa que interrogar a la naturaleza, interpretar sus respuestas y descubrir sus secretos. "La sutileza de las operaciones de la naturaleza _-dice Bacon- sobrepasa infinitamente la de los sentidos y el entendimiento." 18 Por eso, no se podrá conocer el "orden natural" siguiendo el ejemplo brillante pero inútil de la sabiduría

16 F. Bacon, Novum organum, I, 1.

17 Ibid., I, 98 .

18 Ibid., I, 10. 
antigua, que se ha mantenido estacionaria durante dos mil años, sino adoptando el modelo de la única forma de conocimiento capaz de progreso y perféccionamiento: el modelo de las artes mecánicas. Como todos sus contemporáneos, Bacon vive bajo el impacto de los grandes inventos y descubrimientos de la edad moderna, en particular, la imprenta, la pólvora y la brújula, que han impuesto un nuevo rumbo a la historia. "Porque estos tres inventos" - escribe Bacon - "han cambiado la faz del globo terrestre y producido tres grandes revoluciones: la primera, en las letras: la segunda, en el arte militar; la tercera, en la navegación; revoluciones de las que se han derivado una infinidad de cambios de toda especie y cuyo efecto ha sido tal que no hay imperio, secta ni astro que parezca haber tenido tanto ascendente, que haya ejercido por así decirlo tan grande influencia sobre las cosas humanas".19 Como todos sus contemporáneos, Bacon está convencido por ello de la superioridad de' los modernos sobre los antiguos.

Con las artes mecánicas aparece la idea del progreso investida de un sentido positivo. El progreso no es sólo el recorrido de una distancia, sino el nombre mismo de la perfección. En esta acepción, la palabra apàrece por primera vez en la locución "progreso de las ciencias": y por las ciencias se entiende no sólo el saber teórico y racional, sino también el saber técnico, práctico, mecánico. Los hombres de la edad moderna tienen clara conciencia de que representan un adelanto de la civilización, de que han abandonado là niñez y la adolescencia para ingresar en la etapa de la madurez. Adoptar para las ciencias el modelo de las artes mecánicas equivale, en último, análisis, a garantizarle la posibilidad del progreso, del perfeccionämieñtó constante. A una concepción providencialista de la historia, se substituye una concepción progresista, fundada en la acumulación de conocimientos y bienes, de inventos y descubrimientos. Por eso el saber es poder: poder de intelección pero también poder de invención.

Pero, ¿hasta dónde puede conducir el progreso? ¿Cuál es el límite del poder humano? Bacon no se contenta con proponer una nueva ciencia y una nueva lógica, sino que imagina la utopía de la "Nueva Atlántida", de la ciudad ideal, construida a partir de los conocimientos que podrían obtenerse con la reforma intelectual que preconiza. Considerando como resuelto el problema del saber, deduce las consecuencias que habrian de producirse en el curso del mundo y en la vida de los hombres, del mismo modo como conocida la ecuación de una curva se puede conocer su comportamiento sin necesidad de trazarla efectivamente. La utopía es así un método de conocimiento, una prospección del futuro a través de la imaginación y de los sueños. Bacon proyecta la "Casa de Salomón", que es el nombre de su ciudad ideal, sóbre la base de conocimientos que todavía no se habían logrado, de técnicas que no habłan sido inventadas, de realizaciones fantásticàs e imposibles, de ilu-

19 Ibid., I, 129. 
siones, aspiraciones y ambiciones tan extraordinarias como irreales. Pero la utopía es también la expresión de un nuevo sentimiento, propio del hombre moderno, que es el sentimiento del optimismo, de la confianza en el progreso, de la esperanza en el advenimiento de un mundo mejor, proyectado por la ciencia y construido por la técnica. El saber viene al socorro de los sueños. Los viejos mitos pueden convertirse en realidad, no por arte de magia sino por el trabajo y el tesón de los hombres, por su poder de invención y creación.

Multitud de leyendas tienen acaso su origen —como señala Schuhl_ en imposibles deseos humanos: la fuente de Juvencia correspondería al deseo de conservar la eterna juventud; la historia del anillo de Gygés expresaría el sueño de volverse invisible; las leyendas de Orfeo o de Eurídice darían curso a la aspiración de viajar al más allá; el mito de fcaro o de las alfombras volantes satisfarian al deseo de viajar por el aire. ${ }^{20} \mathrm{La}$ nueva ciencia pone al servicio del hombre el prodigioso poder de transformar sueños e ilusiones imposibles en vivientes realidades. La utopía de la "Nueva Atlántida" parece haberse cumplido en la civilización contemporánea, como si la "Casa de Salomón" hubiese sido construida no en una isla perdida, sino a la escala del universo entero. Por eso mismo, confrontada con la historia real, la "Nueva Atlántida" tiene casi el valor de una descripción anticipada del mundo actual.

La "Nueva Atlántida" es el relato de un viaje imaginario por el Pacifico, cuyo punto de partida es el Perú y cuyo destino es China y Japón. Los viajeros, que habian permanecido un año en el Perú, seguían la ruta hacia el Oriente, cuando les sobrevienen las aventuras que narran en el libro. Que Bacon haya elegido el nombre del Perú, no está desprovisto de intención ni de significación. En los siglos xvir y siguientes, el Perú es el símbolo de la riqueza, el pafs encantado de la prosperidad, donde todo es oro y piedras preciosas. Dentro de la economía del relato, su presencia tiene el valor de un término de comparación, puesto que la "Nueva Átlántida" no es un don de la naturaleza, como podría serlo el Perú de la leyenda y del mito, sino una construcción humana, hija del conocimiento y de las artes. Los vientos desvían a los viajeros y los conducen inopinadamente hacia una isla desconocida, donde son aceptados como huéspedes, tras de haber satisfecho las condiciones impuestas por "sus habitantes. La "Nueva Atlántida" es la relación de lo que vieron los viajeros, imitada tal vez de las relaciones que comenzaban a publicarse en 'Europa y que consignaban las noticias y testimonios acerca de las tierras descubiertas por los grandes navegantes. La isla es el reino de Salomón. Es un país cristiano, poblado por gente venida de varias naciones, desde tiempos remotos. Si llevaba el nombre de Salomón, era en homenaje a su más grande legislador, "un príncipe" —dice Bacon_- "cuya

${ }^{20}$ Cfr. Pierre-Maxime Schuhl, Le merveilleux, la pensée et l'action (Paris: Flammarion, 1952), pp. $3^{6-37}$. 
memoria reverenciamos hasta la adoración, no por un entusiasmo supersticioso sino porque este gran personaje, aunque mortal, fue para nosotros el instrumento de la Divinidad". ${ }^{21}$ El territorio de la isla ha sido proyectado y edificado como una gigantesca casa, con los varios aposentos de una habitación, pero también con torres de gran elevación y subterráneos extensos y profundos. Por eso la isla se lláma la "Casa de Salomón".

Este fabuloso país está organizado como una sociedad contractual, voluntaria, cuyos miembros se asignan como misión principal "el descubrimiento de las causas y el conocimiento de la naturaleza intima de las fuerzas primordiales y de los principios de las cosas, con el objeto de extender los limites del imperio del hombre sobre la naturaleza entera y de ejecutar todo lo que es posible".22 La sociedad de Salomón no es sólo una comunidad de hombres sino una ciudad, una nación, un colegio -el "Colegio de los seis días"-, un laboratorio de experimentación, una fábrica y un centro de investigaciones. Lo natural y lo artificial se confunden. Bacon ilustra aquí su doctrina fundamental acerca de la ciencia y de su misión - de la ciencia solidaria de la técnica y de la industria. A diferencia de la concepción aristotélica, que atribuía a la técnica una función secundaria y servil, cuya intervención es siempre precaria y subordinada a la naturaleza, Bacon imagina una técnica autónoma, capaz de contrariar y violentar el curso de los procesos naturales y de ejecutar todo lo que es posible. Consecuentemente, los límites mismos de lo posible se extienden hacia el infinito. Lo posible no está contenido por las leyes naturales ni circunscrito por las fronteras del mundo perceptivo. Lo posible incluye hasta lo inconcebible.

Antiguas quimeras de los hombres son realidad en la "Casa de Salomón": prolongar la vida, fabricar especies animales, volar por los aires, vencer al océano, producir la riqueza y la abundancia. Los subterráneos de la "Casa de Salomón" no sólo conservan materiales de diversas especies sino que sirven para curar ciertas enfermedades y conservar la vida de los hombres, sustrayéndolos a la acción del sol. Sus altas torres son centros de observación de vientos, lluvias, nieves y otros "meteoros". Sus lagos de agua dulce o de agua salada, naturales $o$ artificiales, contienen todas las variedades de peces; y sus corrientes sirven para poner en movimiento artefactos y máquinas. En los pozos y fuentes artificiales se encuentran substancias con propiedades que sirven para las infusiones $y$ de donde se extrae en particular "el agua del parafso", una bebida que contribuye a la conservación de la salud o a la prolongación de la vida. Algunos eciificios.de la isla se utilizan-para la fabricación artificial de la nieve, la lluvia, el granizo, así como del trueno y los relámpagos. En los hospitales o salas de salud se sabe "modificar el aire a

.21 F. Bacon, Oeutres, trad. Buchon, p. $5^{88}$.

22 Ibid., p. 596 . 
voluntad", para curar algunos males o para conservar la salud. ${ }^{23}$ Los jardines, los parques, las plantaciones, producen todas las especies vegetales, no sólo las que crecen naturalmente sino las que han sido generadas por injertos y por combinaciones de"especies. "Nosotros poseemos también" - dice el funcionario de la "Casa de Salomón"_- "medios para volver a las flores y a los frutos de estas plantas, de estos árboles o de estos arbustos más precoces o más tardíos, pero sobre todo para acelerar la germinación, el crecimiento, el florecimiento y la fructificación de los vegetales. Tenemos procedimientos para obtener frutos más grandes o de un gusto más agradable, de un sabor, olor, color o figura diferentes de los que tienen de ordinario. Modificamos algunos para darles propiedades medicinales. Disponemos además de métodos para producir diferentes especies de plantas, sin estar obligados a sembrarlas y por la sola combinación de tierras de diversa clase. Poseemos también métodos para producir plantas nuevas y diferentes por completo de las especies conocidas. 'Por último, logramos transformar árboles o plantas de una especie en vegetales de otra especie". ${ }^{24}$

En la "Casa de Salomón" hay parques para animales terrestres, aves y pájaros de todas las especies, no sólo para satisfacer el gusto por la rareza sino también para las experiencias de "anatomía comparada". ${ }^{25}$ Los habitantes de la isla pueden producir así variedades de animales que -al'igual que las plantas - son "las más singulares en su color, su figura, su temperamento, su locura, su actividad, etc.". Los animales, las plantas, los minerales, son modificados y transmutados según la voluntad humana, tanto para satisfacer las necesidades de la vida como para obtener nuevos conocimientos acerca de la naturaleza. "Ahora bien, todos estos resultados" - dice por eso el dignatario de la isla - "no los obtenemos por azar sino que sabemos de antemano cuál será el producto de nuestras operaciones; podemos decir con certeza que, combinando juntas tales especies de materia y por tal procedimiento, produciremos tal especie de animal." 26 Bacon admite, por lo tanto, la idea de que se puede interrumpir y violentar el curso de la naturaleza sin menoscabo de la vida, de que se puede modificar artificialmente la generación natural y producir nuevas especies y variedades. Es una idea audaz y revolucionaria, que revela una extraordinaria confianza en las posibilidades del conocimiento y de la técnica.

Por otra parte, "los sabios de la "Casa de Salomón" conoceń procedimientos para extraer"la savia de los árboles, para fabricar licores y bebidas prodigiosas, para madurar el agua y transformarla en sabrosa y nutritiva, para fortalecer el cuerpo con alimentos que lo hacen capaz de soportar largos

23 Ibỉd., p. $\overline{597}$.

24 Ibid., p. 598.

25 Ibid., p. 598-9.

26 Ibid., p. 598. 
ayunos, para preparar remedios y drogas que curan las enfermedades, para producir todos los grados de calor, todas las especies del color, todas las formas de la luminosidad, todos los tonos del sonido. "En otra pärte de nuestras casas" - dice el mismo funcionario-, "parte dedicada a la mecánica, se encuentran máquinas e instrumentos destinados a producir movimientos de toda clase. Producimos movimientos más vivos y más veloces que todos aquellos que ustedes podrían producir con ayuda de sus armas de fuego y otras máquinas de ese género. Sabemos cómo facilitar esos movimientos y aumentar su fuerza con ayuda de ruedas y otros medios semejantes, aunque la fuerza motriz tenga poca intensidad. Sảbemos aumentar la fuerza hasta el punto que superan de.lejos a los movimientos producidos por los cañones de ustedes; con sus morteros o con lo que llaman máquinas infernales. Disponemos también de artillería pesada y de instrumentos de guerra de toda clase, a to que hay que agregar una especie de pólvora particular, cuya composición es diferente de la que ustedes conocen, así como también fuegos greguiscos (i. e., fuegos inventados por los griegos para incendiar las naves), susceptibles de encenderse incluso en el agua e inextinguibles; por fin, fuegos de artificios de todo género; ora para el simple placer del espectáculo; ora para el ataque y la defensa. Imitamos el vuelo de los pájaros y podemos hasta cierto punto viajar por el aire. Tenemos, además, ciertas naves o barcos con los que se puede navegar bajo las aguas; y otras embarcaciones que resisten mejor que las de ustedes a la violencia de las olas. En este mismo edificio se ven relojes y péndulos, de una construcción muy ingeniosa y delicada, así como máquinas que son puestas en movimiento por el aire o por el agua, y por donde esos fluidos, reanimando el movimiento por una especie de circulación, lo mantienen por mucho tiempo; por último, en nuestra sección de física se ven también algunos movimientos perpetuos. Imitamos el movimiento de los animales con ayuda de autómatas, cuyas formas son semejantes a las del hombre, los animales terrestres, los pájaros, los peces, las serpientes, etc. $Y$, en fin, producimos por diferentes medios una infinidad de movimientos muy diversificados, cuya fuerza y delicadeza superan, todo lo que es posible imaginar".27 Con tales instrumentos mecánicos, :1a "Casa de Salomón" aparece como una anticipación de la civilización técnico-científica, que predómina en la época actual y cuyo desenvolvimiento futuro es absolutamente imprevisible. Es una civilización que presupone la solución de los problemas teóricos planteados por el movimiento y sus diversas formas, por la utilización de las fuentes posibles de energía, por la transformación tecnológica de los elementos naturales. Para la mayoría de máquinas y artefactos, Bacon se ha inspirado en un principio de construcción fundamental: el arte imita a la naturaleza. No es sólo imitación de formas, sino imitación de movimientos y funciones. La naturaleza es entonces la norma constructiva de la

27 Ibid., p. 602. 
técnica. Desde el punto de vista de la práctica, Bacon podría decir lo mismo que habría de afirmar más tarde Descartes desde el punto de vista de-la teoría: todas las cosas que son artificiales, son con ello naturales, puesto que la naturaleza proporciona el modelo formal y funcional, así como los elementos materiales. Las razones no son, sin embargo, las mismas. Para Descartes el organismo es una máquina. Para' Bacon, la máquina es un organismo; y es un organismo en cuanto resulta de la imitación de la naturaleza, maestra de las artes y del conocimiento. Por esta razón, el experimentalismo de Bacon significa, en última instancia, el retorno a la naturaleza como fuente del saber e inspiración permanente de la acción humana. En ello radica el poder de la ciencia. La utopía de la "Nueva Atlántida", en lo que respecta a la invención técnica, ha sido construida, en consecuencia, mediante la extensión, radicalización y prolongación del poder cognoscitivo del hombre. La técnica no es sólo - como lo era para el mundo antiguouna potenciación de las facultades humanas, sino una facultad humana recién descubierta: la facultad de transformación del mundo material. "Producir en un cuerpo dado" - dice por eso Bacon- "una "nueva naturaleza (modo o manera de ser) o ensamblar nuevas naturalezas sobre una base material propuesta es la obra y el fin del poder humano. En cuanto al descubrimiento de la forma de la naturaleza, de su verdadera diferencia, de su naturaleza naturante o en fin de su fuente de emanación, porque no logramos encontrar sino estos términos que indican más o menos lo que tenemos en mente; este descubrimiento es la obra propia y el fin de la ciencia hümana".28 (La expresión "naturaleza naturante" [natura naturans], se opone a la paralela "naturaleza naturada" [natura naturata]. Su origen se remonta a la filosofía medioeval. La natura naturans es Dios, como creador y principio de las cosas; la natura naturata es el conjunto de cosas y leyes creadas por Dios. Bacon utiliza el término - según Lalande en su "vocabulario filosófico" - en el sentido de "la disposición o el -proceso reales que aparecen a nuestros sentidos bajo el aspecto de una cualidad perceptible, o naturaleza".)

La "Nueva Atlántida" es la primera utopía científica de la historia. Ia ciudad ideal que diseña constituye una espléndida representación de las posibilidades que pone el saber en las manos, del hombre. La "Casa de Salomón" no es sólo científica en sus afanes y obras, sino también en su organización como sociedad. Sus miembros se consagran sólo al saber, entendido como aprendizaje, investigación, invención y experimentación. La naturaleza es campo de observación y de instrucción, pero también maleable, susceptible de infinidad de transformaciones, de tantas transformaciones cuantas es capaz de producir el poder conjugado de la imaginación y de la razón, lo que no es posible sin el supuesto capital de la secularización del mundo, que es característica de la mentalidad moderna: La secularización del mundo

28 F. Bacon, Norum Organum, II, 1. 
no es sólo la promoción de los valores profanos y propiamente humanò sino el expreso recohocimiento de $\mathrm{de}_{\text {su }}$ legitimidad. Pero la "Casa de Salomón" ilustra también la idea de la ciencia como quehacè colectivo y no sólo:como creación solitaria y aislada. La ciencia es obra de una comunidad, esfuerzo compartido, trabajo orgànizado. La ciencia es conservación e innovación. En la "Cása de.Salomón" unos miembros se destinan a mantener la tradición del saber, otros trabajan para alcanzar nuevas artes y nuevos conocimientos, otros por último recogen del resto del mundo informaciones acer? ca de los logros y descubrimientos científicos. "Doce de nosotros". -dice sel director de la sociedad- "están encargados de viajar por los países extranjeros, pero bajo nombres de otras naciones, porque ocultamos con cuidado a todas las otras el conocimiento de la nuestra. Los viajeros : tienen la orden de recoger de las comarcas que hayan recorrido máquinas, instrumentos, muestras, modelos, experiencias y observaciones de todar especie; a. ellos los llamamos comerciantes de luces". ${ }^{29}$. La ciencia exige el comercio de las ideas; intercambio de experiencias, acumulación de informaciones: La comunidad científica no tiene otras fronterás que el universo entero.

Con la utopía de la "Nueva Atlántida" estaba prefigurada; en el alba misma de la ciencia moderna, la imagen del mundo por venir. Tres siglos han bastado para que la utopía sear'casi una realidad. Tres siglos de progreso constante, cada vez más acelerado y vertiginoso. Pero también tres siglos de crisis y revoluciones, que han afectado a la ciencia en sus principios y fundamentos. La historia ha puesto en eviōencia la verdad de las doctrinas de Bacon y Descartes. Bacon es autor del proyecto de la ciencia moderna. Descartes lo es de su principio. En lo esencial se ha cumplido el principio cartesiano de la ciencia como teoría de la realidad, así como se ha cumplido el proyecto baconiano de la ciencia activa y operativa, instrumento intelectual de transformación material. La explicitación del principio cartesiano ha conducido a la matematización creciente del saber en todas sus formas. El desenvolvimiento del proyecto baconiano ha culminado en la constitución de la técnica moderna y en sus prodigiosas realizaciones. Descartes representa el de la práctica. Pero el principio de la ciencia no es inconciliable con su proyecto. El principio es el fundamento de un proceso o de una evolución. El proyecto es un quehacer y una elección. La técnica ha hecho posible la conciliación del fundamento de la ciencia con la tarea que se había asignado. Lo ha hecho posible mediante la traducción en la práctica de los resultados de la teoría. La teoría no se opone entonces a la práctica -como en el mundo antiguo-, sino que por mediación de la técnica se ha establecido entre ambas un conjunto de complejas relaciones, de intercambios e interferencias, que nó sólo las ha potenciado en su eficacia, sino que las ha transformado en isu estructura y en su actividad. La explicación de este 29 F. Bacon, Oeuvres, trad. Buchon, p. 602. 
proceso constituye uno de los problemas fundamentales del pensamiento actual. Es el proceso de una triple transformación: la transformación del mundo; la transformación de la ciencia y de la técnica; y la transformación de la razón. Tres transformaciones cuya interna unidad y cuyo resultado últimó es la transformación del hombre, de su idea, de su proyecto y de su destino.

No hace todavía medio siglo escribía Paul .Valéry: "Actuar a distancia; fabricar oro; transmutar los metales; vencer a la muerte; predecir el porvenir; desplazarse en los medios prohibidos a nuestra especie; hablar; ver, oír de un rincón del mundo a otro; ir a visitar los astros; realizar el movimiento perpetuo, qué sé yo -hemos hecho tantos sueños que su lista sería infinita. Pero el conjunto de estos sueños forma un extraño programa, cuya prosecución está como ligada a la historia misma de los humanos." ${ }^{30}$ Desde la última guerra, muchos de los sueños que Valéry enumeraba se han cumplido de una u otra manera en el breve lapso de una generación- de una generación cuya càpacidad de asombro así como de adaptación parece haberse agotado con la sucesión acelerada de invenciones y descubrimientos, de conocimientos e ideas, de teorías cada vez más audaces y de conquistas cada vez más sorprendentes. Si los sueños de los hombres forman un "extraño programa", no es porque en conjunto han poseído una coherencia interna original, sino porque la ciencia los ha asumido en su proyecto, confiriéndoles su propia racionalidad.. A la lúz del mundo contemporáneo la ciencia aparece como el instrumento más eficaz para realizar las quimeras, ambiciones e ilusiones humanas. A la magia se le atribuía antiguamente el poder instantáneo e ilimitado de transformar a la medida de los deseos todo cuanto existe. La ciencia de hoy es acaso la encarnación moderna de la magia, portadora de sus prestigios y pretensiones, pero también de sus terrores, amenazas y maleficios.

\section{La transformación del mundo}

¿Cómo se ha operado la transformación del mundo? ¿Cómo se ha realizado el proyecto de la ciencia moderna? No se explica la inconcebible acumulación de conocimientos e invienciones sin un procedimiento, un método, cuya aplicación racional ha sido responsable del progreso y de su aceleración. No se la.explica tampoco sin la intervención de una multitud de factores; cuya organización, cuya articulación y cuya convergencia en el cumplimiento de un mismo cometido, han sido deliberadas y conscientes. El mundo actual es el resultado de un proyecto coherente, de un sistema de necesidades y aspiraciones. Es el resultado, en última instancia, del trabajo de lá razón. Un trabajo paciente, obstinado, ininterrumpido. La razón ha impuesto por do-

${ }_{30}$ Cf. Paul Valéry, Variété (Paris: Gallimard, 1924), p. 18. 
quier su disciplina y sus reglas. Con ellas se explican los fenómenos, pero también se fabrican artefactos e instrumentos. Una misma facultad humana ha transformado al mundo $y$, al propio tiempo, lo ha hecho inteligible.

El poder de intelección y transformación, inherente a la razón, se encarna en la ciencia moderna. Bacon había realzado la potencia transformadora de la ciencia y sus consecuencias para la vida humana. Descartes, por su parte, había realzado su potencia intelectiva, la que se ejerce por abstracción, deducción y explicación. Considerando la evolución histórica de la ciencia, Bacon y Descartes - lejos de excluirse recíprocamente- se han vuelto rigurosamente complementarios. En virtud de esta complementaridad, Ia ciencia no ha evolucionado hacia la conciliación de Bacon y Descartes sino más bien hacia la radicalización de las tendencias que ambos representan. Para Bacon el ideal de la ciencia es lá imitación de las artes mecánicas, así como para Descartes lo es la imitación de las matemáticas. Por ello, es la ciencia actual abstracta y formal como las matemáticas, pero al mismo tiempo es técrica y eficaz como las artes mecánicas. La imitación de las artes mecánicas encadena a la ciencia tanto a la industria como al trabajo y la convierte en factor decisivo de la evolución económica y social. La ciencia interviene en la industria mediante la máquina y el artefacto, cuando sus esquemas abstractos se transforman, por obra de la técnica, en instrumentos operativos, que coadyuvan al esfuerzo de los hombres y, al cabo, tienden a reemplazarlo ventajosamente. No se explica, en consecuencia, la transformación del mundo sin la cooperación entre la ciencia y la técnica, sin su labor conjugada y mancomunada, sin la potenciación de sus posibilidades. Esta interacción tecno-científica se revela sobre todo ejemplarmente en el proceso de la fabricación de utensilios y aparatos, que es el trabajo predominante de la civilización contemporánea.

En su libro Science et société, Evry Schatzman hạ descrito este proceso 'con claridad. Sea por ejemplo la fabricación de refrigeradores, artefacto que es uno de los símbolos y de los ídolos de la llamada "sociedad de consumo". "La producción de frío a bajo costo - dice Schatzman- es un privilegio de los tiempos modernos. Luis XIV hacia venir de Noruega barcos cargados de hielo y helados y sorbetes han sido por mucho tiempo manjares de lujo."

La historia moderna del frío comienza en el siglo xix con el abandono de la noción de lo calórico, fluido misterioso que penetra a todos los cuerpos, con la medida de las cantidades de calor, y con la determinación del equivalenté mecánico de la caloría por Joule y Robert Meyer. El estudio de los cambios de estado permite poner en evidencia la existencia de un calor latente de vaporización, cantidad de calor necesario para vaporizar a un líquido en equilibrio con su vapor. Un razonamiento simple permite entonces comprobar que, si se vaporiza a un líquido por aspiración mediante una bomba al vacio, el calor de vaporización no puede ser tomado sino del 
líquido mismo, que se enfría hasta eventualmente volverse hielo. La máquina de Cullen (1755) es una invención a mitad de camino entre el aparato de demostración, el juguete de la ciencia-entrenamiento y la máquina de fabricar hielo. Ella reposa, sin embargo, sobre el conocimiento de las leyes de cambio de estado. En otros términos, al principio de la máquina para fabricar el frío es un principio físico, inconcebible sin las leyes a las que obedece un proceso natural.

Producido durante mucho tiempo por máquinas poderosas, reservado por consiguiente a la producción industrial, el frio ha entrado en la vida familiar gracias a los perfeccionamientos de la industria eléctrica, que ha permitido la realización de motores pequeños; de la química, que ha permitido la producción fácil de líquidos cómodos de vaporizar y fluidificar; y de la calorifugación, que ha permitido la fabricación de buenos aisladores térmicos bajo espesores que no sean prohibitivos. En una época determinada, una refrigeradora, en su realización, esto es, en el aspecto que presenta: dimensiones, forma, color, es el producto de cierto nivel técnico. Los aparatos industriales de hace cincuenta años eran de grandes dimensiones, servian más a menudo a la fabricación del hielo que a la conservación de los alimentos y poséan espesos tabiques de madera para aislar el interior del exterior. La pequeña refrigeradora doméstica de cuarenta litros es un lindo mueble que hace menos ruido que un gato que ronronea. Las espumas de plástico que rellenan sus dobles tabiques son mejores aisladores que las espesas planchas de antaño.

El constructor de máquinas para fabricar el frío, preocupado por extender su mercado, ha tratado de multiplicar formas, dimensiones, usos de máquinas. Pero a través de la multiplicidad de esas realizaciones técnicas, es siempre el mismo principio físico que es utilizado, son siempre las mismas leyes de la termodinámica que son aplicadas. La diferencia es evidente entre los diferentes tipos de conocimiento que sirven en la fabricación de un objeto. Esmaltes vitrificados sobre metal, materias plásticas, motores pequeños, flúidos vaporizables, espumas de plástico aisladoras, el constructor toma técnicas de todas partes. Algunos de estos procedimientos pueden "resultar de la aplicación de leyes físicas o químicas, pero la mayor parte no son en realidad debidos sino a una sucesión de descubrimientos prácticos por el viejo método de los ensayos y errores.

Hace buen tiempo que se sabe luchar contra el frio: los espesos muros de piedra, los rollizos son una mejor protección que una delgada pared de ladrillo o una tela de carpa. Es necesario sin embargo esperar a Fourier y su teoría matemática del calor (1815) para que se comprenda el papel que desempeña la naturaleza del material y su espesor. Ensayos y errores hacen aparecer la función del aire aprisionado, cuyas medidas confirman que es mal conductor del calor. La idea de aumentar el volumen del aire y disminuir la masa del material sólido que lo retiene, hace aparecer a los mate- 
riales fibrosos como la lana de vidrio o toda una variedad de espumas y precipitados solidificados: el merengue es finalmente un excelente aislador. Hay todo un empirismo, que no debe nada o casi nada al conocimiento teórico presente de hecho en la realización de los tabiques de refrigeradoras. Es conocimiento de lo que sale bien y de lo que no sale bien y se emparenta con la receta y el procedimiento. En el límite, un conocimiento empírico de lo que sale bien y tiene éxito no es diferente de la receta de cocina, que nos dice cuáles son làs mezclas aceptables y los'tiempos de cocimiento deseables, salvo que la satisfacción del gusto tiene un carácter subjetivo mientras que el éxito técnico se puede medir.

Acabamos de hacer aparecer una distinción esencial entre dos especies de conocimiento: el conocimiento de una ley (por ejemplo, una ley de termodinámica) y el conocimiento de una receta (por ejemplo, la elección entre la lana de vidrio y una espuma sólida). "Desde el punto de vista de la fabricación de un objeto, el éxito es esencial al objetivo que se ha propuesto.' A este respecto, el conocimiento de una receta no es menos importante que el conocimiento de:la-ley. Pero el conocimiento de la ley tiene sin embargo. un carácter más fundamental, puesto que permite conocer las razones del éxito. Es frecuente que el descubrimiento de leyes de los procesos: naturales permita comprender repentinamente porqué tal o cual recetà garantiza el éxito." ${ }^{31}$

La fabricación de artefactos y utensilios, de objetos técnicos en general, se muestra al análisis como un proceso complejo, discontinuo y abierto. Es un proceso complejo porque admite una multitud de factores distintos $\dot{y}$ heterogéneos, desde las recetas empíricas hasta las leyes universales, desde la observación trivial y nimia hasta la abstracción más elevada, desde la habilidad individual hasta el automatismo de instrumentos y máquinas. Tan importante es, por ejemplo, en la fabricación de refrigeradores, el conocimiento teórico del punto de ebullición de los líquidos como el conocimiento .práctico de las materias aislantes y, en particular, de las materias plásticas. No hay relación directa entre los principios de la termodinámica, descubiertos con ocasión del estudio de las máquinas de vapor, y el conocimiento de las propiedades de las fibras sintéticas, derivado de la actividad industrial. No hay relación tampoco entre la investigación acerca de los agentes refrigerantes y la construcción de motores eléctricos. Sin embargo, la termodinámica, las fibras sintéticas, los agentes refrigerantes y los motores eléctricos;, participan como factores decisivos en la fabricación de refrigeradoras. De aquí resulta que la fabricación no sólo está regida por la ciencia y la técnica, sino por consideraciones muy diversas, económicas, industriales, estéticas, geográ: ficas, incluso políticas y militares, que aumentan su grado de complejidad. hasta alcanzar proporciones gigantescas. La fabricación es además un proceso

31 Evry Schatzman, Science et sociẹte (Paris: Ed. Robert Laffont, 1971), pp. 26-30. 
discontinuo, porque evoluciona mediante saltos y rupturas. Los objetos técnicos no se perfeccionan mediante el desenvolvimiento de sus posibilidades internas, sino mediante la construcción de otro esquema. de fabricación, lo que equivale en definitiva a la creación de un nuevo objeto técnico, que desempeña la misma función que el precedente, pero que es esencialmente distinto. El arcabuz antiguo y el fusil ametrallador de hoy sirven a los mismos fines destructivos, pero no se podría discernir continuidad alguna entre sus respectivos procesos de fabricación. Entre la máquina de fabricar hielo de comienzos del siglo y la refrigeradora moderna, no sólo existen diferencias externas, concernientes a su forma y dimensiones, sino diferencias fundamentales en su constitución material, en su régimen de funcionamiento, en su estructura mecánica y en su utilización práctica. La refrigeradora no es una versión perfeccionada de la antigua máquina de fabricar hielo. Aunque se apoyen en los mismos principios científicos, no responden sin embargo a los mismos esquemas de fabricación. Desde el punto de vista técnico, la creación recibe a menudo el nombre de perfeccionamiento. Por último, la fabricación 'es un proceso abierto, porque ninguna solución técnica es definitiva." Ninguna actividad humana es acaso tan sensible a la innovación como los procesos de fabricación. En razón de la diversidad de factores que intervie-' nen, basta que uno de ellos sea transformado, perfeccionado o reemplazado, para que el proceso en su conjunto experimente considerables modificaciones. Variáciones insignificantes en apariencia de uno de los factores pueden aparejar insospechadas consecuencias, que transtornan todo el régimen de producción. En el siglo pasado, Henry Maudsley, un ingeniero inglés, perfeccionó el torno mecánico inventando un dispositivo denominado slide rest, soporte de corredera, que habria de determinar una verdadera revolución en. la construcción de máquinas-útiles. "Este instrumento mecánico" — dice Marx en El Capita L "no sólo reemplaza a un utensilio particular, sino también a la mano del hombre, que no logra producir formas determinadas sino dirigiendo y ajustando el filo de su instrumento contra o sobre el material de trabajo, como por ejemplo, el hierro. Así se logra producir las formas geométricas deseadas con un grado de exactitud, facilidad y velocidad que ninguna experiencia acumulada podría prestar a la mano del obrero más hábil". ${ }^{32}$ Un tratado técnico de la época, citado por Marx, destaca así la importancia fundamental del slide rest: "Por simple y por poco importante que pueda parecer exteriormente este accesorio del torno, no se afirma nada en exceso sosteniendo que su influencia sobre el perfeccionamiento y la extensión del maquinismo ha sido tan grande como la influencia de las mejoras introducidas por Watt. en. la máquina de vapor. Su introducción ha tenido por efecto perfeccionar todas las máquinas, hacer bajar su precio y estimular el

32 Karl, Marx, Das Kapital (Berlin: Erster Band, Detz Verlag, 1953), p. 403. 
espíritu de invención." ${ }^{33}$. Este-ejemplo revela que en materia de fabricación cualquier leve transformación del esquema técnico, de los mecanismos, de las herramientas, del material mismo, puede determinar transtornos y conmociones de incalculablé magnitud. En la época actual, el descubrimiento de las materias plásticas y la extraordinaria diversidad de sus usos aparece como uno de los factores, fundamentales del progreso técnico y científico. La llamada "sociedad de consumo" no sería acaso concebible sin la existencia del plástico.

La contribución de la ciencia al proceso de fabricación de los 'objetos técnicos se ha operado en el sentido de la racionalización de métodos, procedimientos, recetas, rutinas y conocimientos. Racionalización significa en . este sentido: sistematización, explicación, integración y fundamentación. En consecuencia, la transformación del mundo ha sido posible no sólo por la promoción de la técnica sino por el nuevo modo de conocimiento inaugurado por la ciencia moderna, un nuevo modo de conocimiento que se funda en la cuantificación y la exactitud que procede por esquemas abstractos, que construye sus propias condiciones de verificación y que, en último análisis, contiene adecuadas estructuras de recepción para los diseños técnicos. Una ley teórica, como el primer principio de termodinámica, que determina el equivalente mecánico del calor, preside el funcionamiento de las máquinas térmicas, no sólo como principió explicativo y heurístico, sino como norma técnica para la construcción de sus meanismos. Por obra de la ciencia y de sus leyes, la fabricación de objetos $y^{2}$ artefactos se convierte en su conjunto de operaciones racionales, ordenadás y concaténadas, cuyos resultados se conocen de antemano. De aquí resulta un nuevo concepto del trabajo humano. EI trabajo ya no es tormento ni pena (Cfr., la etimologia: trabajo viene de "tripalium", instrumento de tortura), sino serie de opéraciones, descomponible en unidades de tiempo y, por consiguiente, cuantificable y medible. El trabajo se asocia así a la construcción del mundo material. Es un esfuerzo racional y, al mismo tiempo, técnico y artístico.

Pero el mundo no se ha transformado, desde la edad moderna hasta la época actual, por una evolución lineal y continua. Si Déscartes y Bacon habían previsto el advenimiento del mundo contemporáneo, si pór deducción racional o por anticipación imaginaria habían podido esbozar sus características, si habían logrado construir un proyecto coherente, nada garantizaba sin embargo la posibilidad de su realización efectiva. "El estado mayor de la ciencia" - escribe Lewis Mumford, refiriéndose a la utopía de Bacon"había elaborado la estrategia de la campaña mucho antes de que los comandantes sobre el terreno hubieran desarrollado una táctica capaz de llevar a cabo con detalle el ataque". ${ }^{34}$ Con esta.imagen militar, Mumford pone de

33 lbid., p. $40 \%$, nota 105 .

34 Lewis Mumford, Técnica y Civilización (Madrid: Alianza Editorial, 1971), p. 75. 
relieve la carencia técnica de los comienzos de la edad moderna. El mundo actual era posible, pero no necesario. Comienza a volverse necesario sólo cuando la máquina y los instrumentos mecánicos hacen su aparición en el escenario de la historia y de la cultura, tras un proceso de gestación de uná nueva mentalidad. Bacon y Descartes habían presentido la importancia capital de la máquina como instrumento efectivo de la transformación del mundo. La máquina es a la vez el agente y el resultado de la mecanización del universo. "Fuese lo que fuese lo que faltara en la perspectiva del siglo xvir no era la falta de fe en la presencia inminente, el rápido desarrollo y la profunda importancia de la máquina. La fabricación de relojes; la medición del tiempo; la exploración del espacio; la regularidad monástica; el orden burgués; los artificios técnicos; las inhibiciones protestantes; las exploraciones mágicas; finalmente el orden, la precisión y la claridad de las ciencias físicas mismas; todas estas actividades separadas, en sí quizá inconsideràbles, habían formado al fin un complejo social y una red ideológica, capaz de soportar el peso inmenso de la máquina y de ampliar más aún sus operaciones. Hacia la mitad del siglo xvi las preparaciones iniciales se habían acabado y los inventos claves se habían realizado." 35

El fenómeno histórico del "maquinismo" no es, por consiguiente, un proceso simple, sino una transformación general de la cultura y del hombre mismo. Un nuevo clima, producto de infinidad de factores, se constituye. Dentro de ese clima, la máquina se introduce en la vida humana y se convierte en el elemento preponderante de la transformación del mundo. Por una curiosa inversión, la máquina -que procede de una nueva forma de pensamiento - se convierte en principio de explicación de todas las cosas. El mecanismo tiene su origen en el maquinismo, pero el maquinismo se justifica con el mecanismo. Concebida primero como herramienta, como prolongación y potenciación del trabajo humano, la máquina evoluciona hasta convertirse en agente autónomo y automático, en instrumento independiente de la fuerza y del control humanos. La herramienta está subordinada al operador y depende de su habilidad o su pericia, mientras que la máquina posee autonomía de acción, funciona por sus propios mecanismos, automáticamente, prescindiendo en lo posible de la intervención humana. Con la aparición de la máquina de vapor, del motor a explosión $\mathrm{y}$, más tarde, de los dinamos, resulta posible transformar la energia y substituir la fuerza del hombre o del animal, incierta, precaria y onerosa, por una fuerza regular, estable, homogénea e incomparablemente superior en potencia. La misma diferencia entre máquina y herramienta desaparece con la invención de máquinas-herramientas, como el torno o la perforadora, que ejecutan automáticamente el trabajo del operador. La máquina de vapor a doble efecto, creada por Watt, no sólo libera la energía y transforma el calor en trabajo, sino que manipula $35^{\circ}$ Ibid., p. 77 . 
herramientas, como las hiladoras mecánicas o las grúas de carga. Lá máquinas hérramienta es el rivial del "obrero, en "una desleál competencia.: Es" insensi: ble, infatigable, eficaz. Por ello se explica también lás violentas protestas dè los "obreros por la introducción, en Inglàterrá, de las primèras máquinas de tejer automáticas. Los obreros destruyen las máquinas, no por espíritu conservador, sino por instinto de conservación porque presienten que serán desplazados, destituidos y condenados al hambrè y a la miseria.

Lá introducción de la máquina en "la ${ }^{2}$ industriá constituye lo que histó ricamente se conoce con el nombre de "primera revólución industrial". "La máquina revoluciona el modo de producción, el régimen de trabajo, el ritmo de explotación de la naturaleza, las formas del intercambio comercial, el sistema de la economía capitalista, los modos de vida y hasta la mentalidad misma de los hombres. "La perturbación del modo de producción én una és. fera de la industria -escribe Marx- determina una perturbación análoga en las otras esferas. Esto se produce primero en las ramas de la industria que, aunque están aisladas por la división social del trabajo, de modo que cada una de ellas produce una mercadería independiente, se entrẻazan sin embargo como fases de un proceso total. Es asi como el hilado mecánicó hă hecho necesâria la revolución mecánico-química de la lavanderia, la imprenta y la tintotería. Asi también la revolución en el hilado del àlgódón ha provó cado la invención de la desmotadora para separar las fibras de esta plantá de sus pepitas, invención que ha hecho posible la producción dêl algodón en la inmensa escala en que hoy se ha vuelto indispensable. La revolución en la industria y la agricultura ha requerido una revolución en las condiciones generales del proceso de producción social, es decir, en los medios de comu nicación y de transporte. Los medios de comunicación y. de transporte de una sociedad que tenía por eje, según la expresión de Fourier, la pequeña agricultura con su economía doméstica y sus oficios urbanos, eran completamente insuficientes para subvenir a las necesidades de la producción manufacturera con su división extendida del trabajo social, su concentración de obreros y medios de trabajo, sus mercados coloniales, tan insuficientes que ha sido menester transformarlos. Asimismo, los, medios de comunicación y tránsporte heredados del período de la manufactura se convirtieron pronto en obstáculos insoportables para la gran industria, con la velocidad febril de sutproducción centuplicada, su lanzamiento continuo de capitales y trabajadorés de una esfera de producción a otra y las nuevas condiciones del mercado universal què "habra creado. Aparte de los cambios radicales" introducidos en lasconstrucción de barcos de vela, el servicio de comunicación y transpoite?fue poco a poco adaptado a las exigencias de la tema de buques a vapor, de ferrocarriles y' telégrafos." Las"masas" enormes "de hierro que fue necesario desde entonces formar, soldar, cortar, taladrar y 
modelar requirieron máquinas ciclópeas cuya creación estaba negada a la manufactura.

La gran industria fue pues obligada a adaptar su medio característico de producción, la máquina misma, y a producir máquinas mediante máquinas. Así se creó ella una base técnica adecuada y pudo caminar por sus propios pies. Con la creciente explotación de las máquinas en los primeros decenios del siglo xIx, el maquinismo se apropió poco a poco de la fabricación de máquinas-herramientas y 'en el segundo tercio del siglo solamente la inmensa construcción de vias férreas y la navegación a vapor oceánica hicieron surgir las máquinas ciclópeeas consagradas a la construcción de los primeros motores. ${ }^{36}$

Este admirable análisis pone al descubierto a la vez la igénesis y la estructura del maquinismo industrial. La máquina revoluciona a la industria. Transforma el modo de producción, concentra medios y recursos y plantea exigencias de orden propiamente mecánico. El sector industrial se nutre de los otros sectores, no sólo porque todos constituyen un único proceso global, sino también porque plantea problemas que la manufactura no puede resolver. La uniformización, la concentración, la mecanización pertenecen a la lógica misma del maquinismo industrial. La máquina a vapor se utiliza primera en la industria textil y conexas, pero su uso se extiende después a los. medios de comunicación y transporte, cuya transformación es requerida por la transformación sobrevenida en la industria y la agricultura por la introducción de la máquina a vapor. El maquinismo industrial aparece así como un sistema de reciprocidades. Inversamente, la industria revoluciona a la máquina. De herramienta se convierte en órgano de producción de otras máquinas. El maquinismo alcanza con ello su máximo grado de desarrollo, puesto que se constituye en un ciclo cerracio, en un círculo que comienza con la máquina y termina con la máquina misma.

La ciencia y la técnica crean la máquina. La industria se apodera de la máquina y se sirve de ella como modo de producción principal y característico. Asf́ se constituye la base material y técnica de la transformación del mundo, cuya forma predominante es la producción de objetos y artefactos. La transformación del mundo se concibe inicialmente como la transformación de la naturaléza. Se trata de dominar a la naturaleza y sús procesos, de conjurar las fuerzas hostiles a la vida humana, de instituir --como quería Bacon- el regnum hominie, el reino del hombre. La primera revolución industrial representa, desde esta óptica, la fase heroica y sacrificada de la transformación de la naturaleza. Es la fase de la acumulación capitalista, cuya sórdida historia ha relatado Marx con implacable objetividad.

La transformación de la naturaleza se opera en esta etapa dentro de los límites de lo natural. No se puede dominar a la naturaleza - decía Bacon-

36 Karl Marx, op. cit., pp. 401-402. 
sin obedecerla, es decir, sin respetar su legalidad interna. Lo natural es la norma y el límite de toda transformación. Por lo mismo, la técnica se define como la imitación de la naturaleza. Peró no se trata de una imitación 'servil, porque la transformación comporta necesariamente la violencia $\mathrm{y}$, en última instancia, la destrucción. Bien "pronto, sin embargo, en virtud de la lógica interna de la técnica, del maquinismo y del capitalismo industrial, el movimiento de transformáción se orienta en un sentido preternaturál, esto es, rebasa la norma de lo natural más allá de todo límite concebiblè. La transformación del mundo no es sólo transformación de la naturaleza sino substitución de la naturaleza. Es el proceso que se inicia con la llamada "segunda revolución industrial", caracterizada por la utilización de nuevas fuentes de energía, en particular la èlectricidad, que promueve, potencia y acelera el progreso técnico, industrial y económico. La diferencia entre lo natural y lo artificial, tan tajante y drástica en el mundo antiguo, tiende a desaparecer. $\mathrm{El}$ artefacto no sólo es rival de las cosas naturales, sino que las substituye y' en cierto modo, las supera. Al lado del mundo natural, la ciencia, la técnica, la industria crean otro mundo insólito y dominante, otro mundo proyectado y construido por los hombres, otro mundo facticio, artificial y mecánico, otro mundo de transformaciones y substituciones.

Después de la última guerra, la aceleración del progreso desafía a la imaginación. Una nueva revolución cientifica, técnica, industrial, conmueve a la humanidad. "La explosión de la ciencia" - dice Jean Pierre Vigier"pasa sobre nuestro mundo como un terremoto. Cuando el polvo haya desaparecido, un mundo muy diferente aparecerá ante nuestros ojos".s7. A medida que se consolidan los efectos de esta revolución, aparece con mayor nitidez el carácter original, radicalmente nuevo, del mundo contemporáneo, cuya existencia constituye una clara ruptura de continuidad con respecto del pasado inmediato. Nuevas cosas, nuevas ideas, nuevos sentimientos, nuevas necesidades, transtornan la vida de los hombres, instalan por todas partes el reino de lo imprevisible y siembran la duda, la confusión o el desconcierto en proporciones desconocidas. Apenas hoy se comienza a cobrar conciencia de que lo contemporáneo no es sólo un límite histórico sino una fuerza irrepresible, inevitable e ineluctable. "Si nos fundamos" — dice Kenneth Boulding"sobre un conjunto de series estadísticas ligadas a las actividades humanas, la fecha que separa a la historia de la humanidad en "dos mitades iguales entra en el campo de los recuerdos de nuestros contemporáneos:.. El mundo de hoy es tan diferente de aquél en que yo nací como éste lo era de la época de Julio César. Años más o años menos, nací en la mitâd dè la historia humana. Desde mi nacimiento se han producido casi tantas cosás como se habían producido antes". ${ }^{38} \mathrm{El}$ mundo contemporáneo se interpreta así como

37 Jean Pierre Vigier, Rinascita, número de junio de 1965.

38 Citado por Alvin Toffler, Le choc du futur (Paris: Denoel; 1971), p. 27. 
el inicio de la verdadera historia, lo que relega a los siglos precedentes a los confines de la pre-historia. La obra de unos pocos años es equivalente a la de siglos de trabajo y creación.

Algunas conquistas de los últimos veinte años dan una idea aproximada de la magnitud del progreso científico y técnico. ${ }^{3 \theta}$

- La velocidad máxima de los vehículos conducidos por los hombres ha sido multiplicada por cerca de $5^{\circ}$, es decir, de 800 a $3^{0} 000$ kilómetros por hora.

- La potencia de los explosivos ha sido multiplicada por 1000 , como en el caso de la energía nuclear.

- La seguridad de funcionamiento de los aparatos electrónicos ha sido multiplicada por 10 con la invención dé los transistores.

-El tiempo de tratamiento de los razonamientos lógicos elementales ha pasado de un millonésimo de segundo a un mil millonésimo de segundo.

- La cantidad de informaciones transmisibles en el espacio sobre un solo soporte hà sido multiplicado por un factor superior a $x$ ooo, con el descubrimiento de los haces modulables de luz coherente y de los rayos láser.

Cada una de estas conquistas determina ya por separado una verdadera revolución no sólo en el ámbito desde donde han surgido, sino en la 'realidad en su conjunto. Reunidas e integradas, constituyen una revolución sin precedentes en la historia, cuyas consecuencias todavía no aparecen con toda nitidez. Multitud de conceptos y supuestos han sido trastocados, revocados' o suprimidos. Incluso la capacidad misma de adaptación humana al cambio parece haber llegado a su límite, como lo señala el libro de Alvin Toffler, Le choc du futur. La transformación del mundo cobra la forma de una riesgosa aventura, de un salto en el vacío, que no excluye ni la destrucción de la naturaleza ni la destrucción del hombre mismo como especie viviente.

Remontando de las consecuencias a los principios, por vía analfitica, la ciencia y la técnica se muesträn como condiciones de posibilidad del mundo contemporáneo. Por lo tanto, la transformación del mundo no se explica sin explicar la transformación de la ciencia y de la técnica. La ciencia de hoy no es la misma que la ciencia de la época moderna. La técnica de hoy no es la misma que la de la edad inicial del maquinismo. La ciencia y la técnica contemporáneas -representan una ruptưra de continuidad en la historia del saber y de la cultura.

UNIVERSTDAD SIMón BoLf́ar

Víctor Li GarRILLO CARACAS, VenEZUELA

39 Cfr. La Documentation Française, Reflexions pour 1985 (Parfs: 1964), p. 114. 